\title{
Risk factors associated with mortality among patients who had candidemia in a university hospital
}

\author{
Priscila Guerino Vilela Alves ${ }^{[1]}$, Sávia Gonçalves Oliveira Melo ${ }^{[1]}$, \\ Meliza Arantes de Souza Bessa ${ }^{[2]}$, Murilo de Oliveira Brito ${ }^{[3]}$, Ralciane de Paula Menezes ${ }^{[4]}$, \\ Lúcio Borges de Araújo ${ }^{[5]}$, Mário Paulo Amante Penatti ${ }^{[4]}$, Reginaldo dos Santos Pedroso ${ }^{[1],[4]}$ \\ and Denise Von Dolinger de Brito Röder ${ }^{[1],[6]}$
}

\begin{abstract}
[1]. Universidade Federal de Uberlândia, Faculdade de Medicina, Uberlândia, MG, Brasil.
[2]. Universidade Federal de Uberlândia, Instituto de Biologia, Uberlândia, MG, Brasil.

[3]. Universidade Federal de Uberlândia, Instituto de Geografia, Uberlândia, MG, Brasil.

[4]. Universidade Federal de Uberlândia, Escola Técnica de Saúde, Uberlândia, MG, Brasil.

[5]. Universidade Federal de Uberlândia, Faculdade de Matemática, Uberlândia, MG, Brasil.
\end{abstract}

[6]. Universidade Federal de Uberlândia, Instituto de Ciências Biomédicas, Uberlândia, MG, Brasil.

\begin{abstract}
Introduction: Bloodstream infection due to Candida spp. is a primary cause of morbidity and mortality in tertiary hospitals. Methods: In this retrospective study, we included patients with a positive blood culture for Candida spp. after $48 \mathrm{~h}$ of hospitalization. Results: A total of 335 patients who had candidemia were included in this study. Risk factors associated with mortality were hospitalization in internal medicine units and surgical clinics, age $>60$ years, mechanical ventilation, orotracheal intubation, hemodialysis, corticosteroids use, and C. parapsilosis infection. Conclusions: This study highlights the importance of health care related to invasive procedures and actions to improve patient immunity.
\end{abstract}

Key words: Candidemia. Risk factors. Mortality.

Bloodstream infection (BSI) is one of the main causes of morbidity and mortality in tertiary hospitals, and $7.9 \%$ to $9.0 \%$ of infections are caused by Candida spp. Approximately $50 \%$ of candidemia cases are caused by C. albicans, followed by C. glabrata complex, C. parapsilosis sensu lato, and C. tropicalis ${ }^{1-3}$.

Episodes of candidemia have occurred mainly among patients who have been hospitalized for long periods of time and have been exposed to antimicrobials drugs, immunosuppressive therapy, parenteral nutrition, and invasive medical procedures. Typically, candidemia has a difficult diagnosis and treatment, a high mortality rate $(40 \%$ to $60 \%)$, and incurs high hospital costs ${ }^{4}$. The incidence rate of candidemia in Brazil ranges from 0.91 to 2.49 per 1000 admissions ${ }^{5}$. This study aimed to evaluate the risk factors associated

\footnotetext{
Corresponding author: Reginaldo dos Santos Pedroso.

e-mail: rpedroso@ufu.br

(D) https://orcid.org/0000-0003-3010-5754

Received 26 April 2019

Accepted 27 April 2020
}

with mortality in patients who had BSI caused by Candida spp. in a Brazilian tertiary care hospital.

A retrospective study was carried out at the Hospital of Clinics of the Federal University of Uberlândia, a tertiary care university hospital with 520 beds located in Minas Gerais in southeastern Brazil. Patients with positive blood cultures for Candida spp., obtained after 48 h of hospitalization, between 2009 and 2016 were included in the study. These patients were selected from the database of the Clinical Analysis Laboratory of the hospital.

Data were collected from medical records and included age, sex, hospital sector, comorbidities, invasive procedures, antifungal therapy use, corticosteroids use, prior antimicrobial therapy, length of hospital stay before blood culture positivity, crude mortality rate, and Candida species. The incidence rate of candidemia per 1000 admissions was calculated through the following equation: total number of patients that had candidemia/total number of hospitalized patients $\times 1000$. The crude mortality rate was calculated through the following equation: total number of deaths in patients that had candidemia/total number of hospitalized patients during the study period x 1000 . 
Blood samples were processed in the Microbiology Unit of the Clinical Analysis Laboratory using the BacT/ALERT® 3D system (Biomérieux, France) and identified by traditional methods (chromogenic medium, micromorphological analysis, and staining of Gram); all species were confirmed using the VITEK ${ }^{\circledR} 2$ system (BD Diagnostic Systems, Franklin Lakes, NJ, USA).

Qualitative variables were expressed as frequencies and percentages, and quantitative variables were expressed as mean and standard deviation. For univariate and multivariate analyses, logistic regression was used, and a $P$-value $\leq 0.05$ was considered statistically significant. All analyses were performed using SPSS software for Windows (version 20.0; IBM Corp., Armonk, NY, USA).

This study included 335 patients who had candidemia between 2009 and 2016, ranging in age from 1 day to 96 years. The incidence of candidemia was 1.36 infections per 1000 admissions, and the crude mortality rate was $54.6 \%$.

Clinical, demographic, and outcome characteristics of the patients are presented in Table 1 . The mortality rate was higher in patients aged over 60 years $(P<0.01)$, those who underwent hemodialysis $(P<0.01)$, and those who required mechanical ventilation $(P<0.01)$ or orotracheal intubation $(P<0.01)$ or had $C$. parapsilosis infection $(P=0.03)$ during hospitalization. Corticosteroids use $(\mathrm{P}<0.01)$, hemodialysis $(\mathrm{P}<0.01)$, orotracheal intubation $(P<0.01)$, mechanical ventilation $(P<0.01)$, and C. parapsilosis infection $(P=0.01)$ were independent risk factors for mortality.

The risk factors related to death and hospitalization are shown in Table 2. Patients hospitalized in the internal medicine unit $(P=0.03)$ and surgical clinic $(P<0.01)$ had a higher incidence of mortality. The majority of patients $(65.1 \%, 218 / 335)$ required treatment in the intensive care unit (ICU) at some point during hospitalization. Furthermore, the following factors were found to be protective in relation to mortality, with an odds ratio (OR) less than 1.00: hospitalization in the emergency unit or pediatric ICU, use of parenteral nutrition, use of fluconazole or amphotericin B and the duration of their use, and total hospitalization time.

Antimicrobial therapy use before diagnosis was documented in $97.6 \%$ of patients. The most commonly used antifungal treatment was fluconazole $(85.4 \%, 286 / 335$ patients). Several patients did not receive antifungal treatment for candidemia $(9.5 \%, 32 / 335)$, and in all cases, the patients died before or on the same day that the positive blood culture result was confirmed for Candida spp.

There were 352 Candida isolates identified, and C. albicans was the predominant species causing BSI $(43.7 \%, 154 / 352)$. The second most prevalent species was $C$. tropicalis $(21.3 \%, 75 / 352)$, followed by $C$. parapsilosis sensu lato $(16.5 \%, 58 / 352)$, C. glabrata complex $(8.5 \%, 30 / 352)$, and C. krusei $(4.0 \%, 14 / 352)$. Other species included C. lusitaniae $(\mathrm{n}=2), C$. famata $(\mathrm{n}=2)$, C. guilliermondii $(\mathrm{n}=5)$, Candida spp. $(\mathrm{n}=14)$, and C. utilis $(\mathrm{n}=1)$, totaling $6.53 \%$ (Figure 1). Seventeen (5.1\%) patients were infected by more than one Candida species.

During the study, patients were at higher risk for mortality if they were hospitalized in the internal medicine unit, were elderly $(>60$ years old), were on hemodialysis, or required mechanical ventilation or orotracheal intubation. It has been previously reported that older patients are more likely to develop hospital infections because of the physiological changes associated with aging, a decline in immune response, and the need for invasive procedures ${ }^{6}$. When patients are subjected to procedures such as mechanical ventilation, orotracheal intubation, and hemodialysis, their microbiota becomes unbalanced and protective barriers are broken, thereby increasing the chance of colonization and nosocomial infection? ${ }^{7}$.

The internal medicine unit is an infirmary where patients with difficult clinical conditions are treated, such as patients who have undergone coronary catheterization and patients who have acute and rare chronic diseases. These conditions depress the immune system and prolong hospitalization time, which increases the risk of infection. A multicenter study in Italy evaluated patients who were hospitalized for candidemia in the medical ward, concluding that patients with a mean age of 76 years with significant risk factors, such as immunosuppressive therapy, previous antibiotic therapy, diabetes mellitus, or severe sepsis, had a hospital mortality rate of $40.4 \%{ }^{8}$.

In this study, the use of parenteral nutrition was identified as a protective factor, representing a lower risk of mortality, thus demonstrating that nutritional care may reduce morbimortality rates caused by malnutrition as well as improve patient prognosis 9 .

The use and duration of antifungal treatments (fluconazole and amphotericin B) were also protective factors. This emphasizes the efficacy of administration of appropriate therapy as a prophylactic or preemptive therapy or as soon as a diagnosis is confirmed ${ }^{10}$, considering all patients with confirmed candidemia who did not receive antifungal drugs died. Those patients who did not receive therapy as soon as the diagnosis was confirmed or in whom the diagnosis was delayed also died. Importantly, fluconazole is not routinely used as a prophylactic in the hospital under study.

The total hospitalization time (days) and hospitalization in the emergency unit were also identified as protective factors. A shorter hospitalization time was directly proportional to a larger survival rate. In the emergency unit, the patient is quickly transferred to other specialized sectors, according to their clinical state.

Furthermore, patients with confirmed candidemia who were admitted to the pediatric ICU had lower mortality rates than did patients suffering from the same infection at other units of the hospital; the unit is a reference throughout the region because of rigid visitor control. The materials used for care are not shared (pressure device cuff, thermometer, stethoscope, among others), and sanitization of hand is a priority in patient care.

On the basis of other studies ${ }^{1,11}$, although C. albicans remains the most frequently encountered species in clinical laboratories, there has been an increase in the frequency of non-C. albicans species, such as C. tropicalis, C. parapsilosis sensu lato, C. krusei, and the $C$. glabrata complex. In this study, the $C$. glabrata complex increased over the years, whereas C. albicans, C. tropicalis, and C. parapsilosis sensu lato remained constant. Non-C. albicans species are known for antifungal resistance, which reinforces the need to implement routine antifungal resistance testing at the study hospital, as it is not part of the current routine. 
TABLE 1: Analysis of clinical and demographic characteristics of patients with candidemia in relation to mortality in a university hospital (2009-2016).

\begin{tabular}{|c|c|c|c|c|c|c|c|c|c|c|c|c|}
\hline \multirow[t]{2}{*}{ Characteristics } & \multicolumn{2}{|c|}{$\begin{array}{l}\text { Survived } \\
(n=152)\end{array}$} & \multicolumn{2}{|c|}{ Death $(n=183)$} & \multicolumn{2}{|c|}{$\begin{array}{l}\text { Univariate } \\
\text { analysis }\end{array}$} & \multicolumn{2}{|c|}{$\begin{array}{c}95 \% \text { Confidence } \\
\text { interval } \\
\end{array}$} & \multicolumn{2}{|c|}{$\begin{array}{c}\text { Multivariate } \\
\text { analysis }\end{array}$} & \multicolumn{2}{|c|}{$\begin{array}{c}95 \% \text { Confidence } \\
\text { interval } \\
\end{array}$} \\
\hline & $\mathbf{N}$ & $\%$ & $\mathbf{N}$ & $\%$ & $P$-value* & OR & Lower & Upper & $P$-value* & OR & Lower & Upper \\
\hline \multicolumn{13}{|l|}{ Age } \\
\hline $0-30$ days $^{a}$ & 15 & 9.9 & 9 & 4.9 & - & - & - & - & - & - & - & - \\
\hline 31 days- 1 years old & 15 & 9.9 & 12 & 6.6 & 0.61 & 1.33 & 0.43 & 4.10 & - & - & - & - \\
\hline$>2-11$ years old & 16 & 10.5 & 4 & 2.2 & 0.21 & 0.41 & 0.11 & 1.64 & - & - & - & - \\
\hline$>12-24$ years old & 12 & 7.9 & 0 & 0 & 0.99 & 1.00 & - & - & - & - & - & - \\
\hline$>25-39$ years old & 18 & 11.8 & 17 & 9.3 & 0.40 & 1.57 & 0.55 & 4.54 & - & - & - & - \\
\hline $40-59$ years old & 49 & 32.2 & 52 & 28.4 & 0.22 & 1.76 & 0.71 & 4.41 & - & - & - & - \\
\hline$>60$ years old & 27 & 17.8 & 89 & 48.6 & $<0.01^{*}$ & 5.49 & 2.16 & 13.95 & - & - & - & - \\
\hline Males & 92 & 50.3 & 91 & 59.9 & 0.07 & 0.68 & 0.44 & 1.04 & - & - & - & - \\
\hline $\begin{array}{l}\text { Surgery of the gastrointestinal } \\
\text { tract }\end{array}$ & 32 & 21.6 & 56 & 30.8 & 0.06 & 1.61 & 0.97 & 2.66 & - & - & - & - \\
\hline \multicolumn{13}{|l|}{ Comorbidity } \\
\hline Renal transplantation & 3 & 2.0 & 1 & 0.5 & 0.26 & 0.27 & 0.02 & 2.65 & - & - & - & - \\
\hline HIV & 4 & 2.8 & 6 & 3.3 & 0.76 & 1.21 & 0.33 & 4.39 & - & - & - & - \\
\hline Neoplasia & 26 & 17.9 & 44 & 24.4 & 0.15 & 1.48 & 0.85 & 2.55 & - & - & - & - \\
\hline Cardiopathy & 9 & 6.2 & 19 & 10.6 & 0.16 & 1.78 & 0.78 & 4.07 & - & - & - & - \\
\hline Diabetes mellitus & 16 & 11.0 & 24 & 13.3 & 0.53 & 1.24 & 0.63 & 2.43 & - & - & - & - \\
\hline Hypertension & 30 & 20.7 & 48 & 26.7 & 0.21 & 1.39 & 0.82 & 2.34 & - & - & - & - \\
\hline \multicolumn{13}{|l|}{ Invasive procedures } \\
\hline Mechanical ventilation & 70 & 47.6 & 121 & 66.5 & $<0.01^{*}$ & 2.18 & 1.39 & 3.41 & $<0.01^{*}$ & 2.18 & 1.24 & 3.72 \\
\hline Tracheostomy & 31 & 21.2 & 38 & 20.9 & 0.93 & 0.97 & 0.57 & 1.66 & - & - & - & - \\
\hline CVC & 137 & 93.2 & 163 & 89.6 & 0.25 & 0.62 & 0.28 & 1.39 & - & - & - & - \\
\hline Nasoenteral catheter & 85 & 57.8 & 108 & 59.3 & 0.78 & 1.06 & 0.68 & 1.65 & - & - & - & - \\
\hline Hemodialysis & 18 & 12.3 & 85 & 46.7 & $<0.01^{*}$ & 6.23 & 3.51 & 11.05 & $<0.01^{*}$ & 5.10 & 2.68 & 9.73 \\
\hline Parenteral nutrition & 71 & 48.3 & 63 & 34.6 & $0.01^{*}$ & 0.56 & 0.36 & 0.88 & - & - & & \\
\hline Colostomy bag & 7 & 4.8 & 14 & 7.7 & 0.28 & 1.66 & 0.65 & 4.24 & - & - & & \\
\hline Orotracheal intubation & 7 & 4.8 & 32 & 17.6 & $<0.01^{*}$ & 4.26 & 1.82 & 9.97 & $<0.01^{*}$ & 4.93 & 1.74 & 14.00 \\
\hline \multicolumn{13}{|l|}{ Antifungal agents } \\
\hline Fluconazole & 134 & 89.3 & 152 & 83.1 & 0.10 & 0.58 & 0.30 & 1.11 & - & - & - & - \\
\hline Time of use (days) ${ }^{b}$ & \multicolumn{2}{|c|}{$11.6 \pm 11.2$} & \multicolumn{2}{|c|}{$15.9 \pm 17.5$} & $0.01^{*}$ & 0.97 & 0.95 & 0.99 & $0.04^{*}$ & 0.97 & 0.95 & 0.99 \\
\hline Amphotericin B & 31 & 20.7 & 18 & 9.8 & $<0.01^{*}$ & 0.41 & 0.22 & 0.78 & - & - & - & - \\
\hline Time of use (days) ${ }^{b}$ & \multicolumn{2}{|c|}{$1.2 \pm 5.1$} & \multicolumn{2}{|c|}{$3.3 \pm 8.0$} & $<0.01^{*}$ & 0.95 & 0.91 & 0.98 & - & - & - & - \\
\hline Micafungin & 23 & 15.3 & 30 & 16.4 & 0.79 & 1.08 & 0.59 & 1.95 & - & - & - & - \\
\hline Time of use (days) ${ }^{\mathrm{b}}$ & \multicolumn{2}{|c|}{$2.1 \pm 6.2$} & \multicolumn{2}{|c|}{$2.2 \pm 6.0$} & 0.84 & 0.99 & 0.96 & 1.03 & - & - & - & - \\
\hline Use of corticosteroids & 70 & 50.7 & 126 & 72.0 & $0.00^{*}$ & 2.49 & 1.56 & 3.99 & $0.01^{*}$ & 2.23 & 1.26 & 3.90 \\
\hline \multicolumn{13}{|l|}{ Species } \\
\hline C. albicans & 70 & 46.1 & 84 & 45.9 & 0.97 & 0.99 & 0.64 & 1.53 & - & - & - & - \\
\hline C. tropicalis & 34 & 22.4 & 41 & 22.7 & 0.99 & 1.00 & 0.59 & 1.68 & - & - & - & - \\
\hline C. parapsilosis sensu lato & 19 & 12.5 & 39 & 21.3 & $0.03^{*}$ & 1.90 & 1.04 & 3.44 & $0.01^{*}$ & 2.51 & 1.17 & 5.40 \\
\hline C. krusei & 7 & 4.6 & 7 & 3.8 & 0.73 & 0.83 & 0.28 & 2.41 & - & - & - & - \\
\hline C. glabrata complex & 14 & 9.2 & 16 & 8.7 & 0.88 & 0.94 & 0.44 & 2.00 & - & - & - & - \\
\hline Others $^{* *}$ & 11 & 7.2 & 13 & 7.1 & 0.96 & 0.98 & 0.42 & 2.25 & - & - & - & - \\
\hline
\end{tabular}

a reference class for the age groups; ${ }^{\mathrm{b}}$ mean \pm standard deviation; ${ }^{*} P \leq 0.05$ considered significant; ${ }^{* *} \mathrm{C}$. lusitaniae, C. famata, $C$. guilliermondii, Candida spp., and C. utilis. OR: odds ratio; ICU: intensive care unit; NICU: neonatal intensive care unit; PICU: pediatric intensive care unit; AICU: adult intensive care unit; CIUC: coronary intensive care unit; CVC: Central Venous Catheters; HIV: Human immunodeficiency virus. - data were not shown because they were not significant for a $P \leq 0.05$. 
TABLE 2: Analysis of the hospitalization of patients with candidemia in relation to mortality in a university hospital (2009-2016).

\begin{tabular}{|c|c|c|c|c|c|c|c|c|c|c|c|c|}
\hline \multirow[t]{2}{*}{ Characteristics } & \multicolumn{2}{|c|}{ Survived $(n=152)$} & \multicolumn{2}{|c|}{ Death $(n=183)$} & \multicolumn{2}{|c|}{ Univariate analysis } & \multicolumn{2}{|c|}{$\begin{array}{c}95 \% \text { Confidence } \\
\text { interval }\end{array}$} & \multicolumn{2}{|c|}{$\begin{array}{c}\text { Multivariate } \\
\text { analysis }\end{array}$} & \multicolumn{2}{|c|}{$\begin{array}{c}95 \% \text { Confidence } \\
\text { interval }\end{array}$} \\
\hline & $\mathbf{n}$ & $\%$ & $\mathbf{N}$ & $\%$ & $P$-value* & OR & Lower & Upper & $P$-value* & OR & Lower & Upper \\
\hline ICU hospitalization & 99 & 65.1 & 119 & 65.0 & 0.98 & 0.99 & 0.63 & 1.56 & - & - & - & - \\
\hline $\mathrm{NICU}$ & 17 & 11.2 & 16 & 8.7 & 0.45 & 0.76 & 0.37 & 1.56 & - & - & - & - \\
\hline PICU & 17 & 11.2 & 7 & 3.8 & $0.01^{*}$ & 0.31 & 0.12 & 0.78 & - & - & - & - \\
\hline $\mathrm{AICU}$ & 65 & 42.8 & 92 & 50.3 & 0.17 & 1.35 & 0.87 & 2.08 & - & - & - & - \\
\hline CIUC & 1 & 0.7 & 2 & 1.1 & 0.67 & 1.66 & 0.14 & 18.58 & - & - & - & - \\
\hline $\begin{array}{l}\text { ICU hospitalization } \\
\text { time (days) }\end{array}$ & \multicolumn{2}{|c|}{$19.9 \pm 30.0$} & \multicolumn{2}{|c|}{$20.0 \pm 24.9$} & 0.97 & 1.00 & 0.992 & 1.008 & - & - & - & - \\
\hline Surgical clinic & 31 & 20.4 & 60 & 33.0 & $<0.01^{*}$ & 1.94 & 1.17 & 3.20 & - & - & - & - \\
\hline Internal medicine & 16 & 10.5 & 34 & 18.6 & $0.03^{*}$ & 1.97 & 1.04 & 3.72 & - & - & - & - \\
\hline Emergency unit & 50 & 32.9 & 29 & 16.0 & $<0.01^{*}$ & 0.39 & 0.23 & 0.66 & $<0.01$ & 0.33 & 0.19 & 0.56 \\
\hline Pediatric & 18 & 11.8 & 4 & 2.2 & $<0.01^{*}$ & 0.17 & 0.06 & 0.51 & $<0.01^{*}$ & 0.14 & 0.05 & 0.42 \\
\hline Oncology & 7 & 4.6 & 9 & 5.0 & 0.87 & 1.08 & 0.39 & 2.98 & - & - & - & - \\
\hline Others & 13 & 8.6 & 17 & 9.3 & 0.78 & 1.11 & 0.52 & 2.36 & - & - & - & - \\
\hline $\begin{array}{l}\text { Hospitalization time } \\
\text { before positive culture } \\
\text { (days) }\end{array}$ & \multicolumn{2}{|c|}{$32.9 \pm 44.3$} & \multicolumn{2}{|c|}{$36.6 \pm 51.8$} & 0.45 & 0.999 & 0.99 & 1.003 & - & - & - & - \\
\hline $\begin{array}{l}\text { Total hospitalization time } \\
\text { (days) }^{a}\end{array}$ & \multicolumn{2}{|c|}{$56.0 \pm 76.6$} & \multicolumn{2}{|c|}{$74.9 \pm 51.4$} & $0.01^{*}$ & 0.999 & 0.99 & 0.999 & $0.04^{*}$ & 0.996 & 0.992 & 0.999 \\
\hline
\end{tabular}

a mean \pm standard deviation; ${ }^{*} P \leq 0.05$ considered significant; OR: odds ratio; ICU: intensive care unit; NICU: neonatal intensive care unit; PICU: pediatric intensive care unit; AICU: adult intensive care unit; CIUC: coronary intensive care unit. - data were not shown because they were not significant for a $P \leq 0.05$.

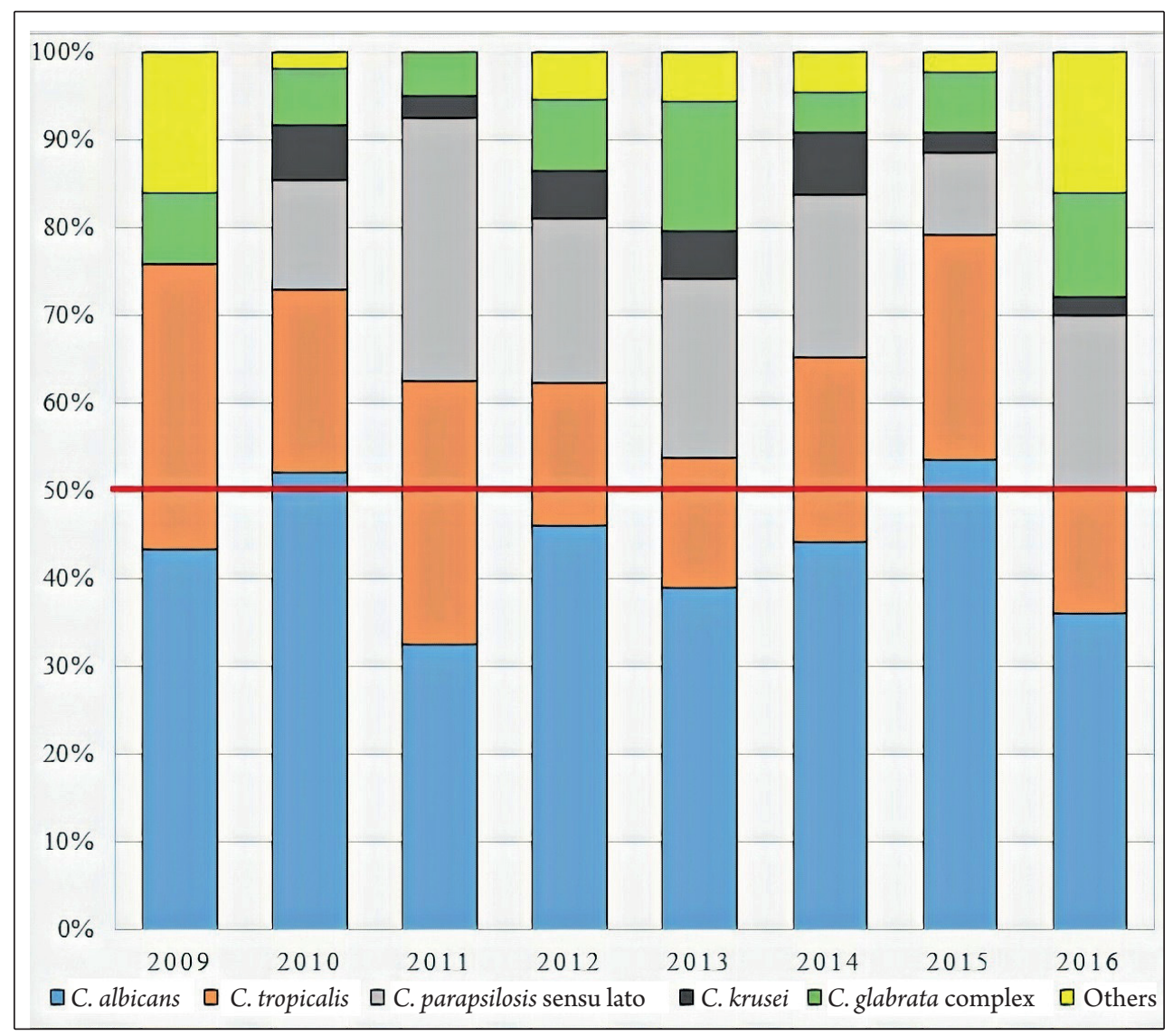

FIGURE 1: Distribution of the 352 identified isolates of Candida spp. over the 8 years of the study. The red line demonstrates the prevalence of non-C. albicans species. ${ }^{*}$ C. Iusitaniae, C. famata, C. guilliermondii, Candida spp., and C. utilis. 
The incorporation of molecular methods for typing nosocomial pathogens has aided efforts to obtain a more fundamental evaluation of microorganisms. Establishing the clonality of pathogens can assist in source identification and distinguish between infectious and non-infectious strains ${ }^{12}$.

C. parapsilosis sensu lato presented significant results for death in this study. Over the last decade, the incidence of $C$. parapsilosis sensu lato has increased. The increased incidence has been attributed to a variety of risk factors, including the body's selective growth capacity in hyperalimentation solutions and its high ability to colonize intravascular devices and prosthetic materials. In addition, patients who require prolonged use of central venous catheters or indwelling devices, such as cancer patients, are at increased risk for C. parapsilosis sensu lato infection ${ }^{13,14}$.

The crude mortality rate was $54.6 \%$, similar to that in several studies conducted in Brazil, China, and Pakistan (50.3-58\%) $)^{5,8,13}$, and higher than that observed in other studies conducted in Brazil and China (37.0-38.1\%) $)^{15,16}$.

The significant risk factors for mortality in patients who had candidemia were the requirement for invasive procedures (mechanical ventilation, hemodialysis, and orotracheal intubation), use of corticosteroids, and C. parapsilosis infection. Non-C. albicans species were the most prevalent causative agents of candidemia. In summary, the results of this study highlight the importance of total hospitalization time, the requirement for care related to invasive procedures, and actions to improve patient immunity, such as a good nutritional balance, which will contribute to reducing the severity of Candida infections and consequently, the morbimortality.

\section{ACKNOWLEDGMENTS}

Special thanks to Tomaz de Aquino Moreira and Lucivânia Duarte Silva Malvino of the Mycology Unit of the Clinical Analysis Laboratory of the Clinical Hospital of the Federal University of Uberlandia for providing information related to screening.

\section{AUTHORS CONTRIBUTION}

PGVA: Study design, development \& methodology, collection of data, data analysis/interpretation, writing all/sections of the manuscript, and manuscript revision; SGOM, MASB, MOB, RPM, and LBA: Development \& methodology, collection of data and data analysis/interpretation; MPAP: Writing all/sections of the manuscript and manuscript revision; RSP: Study design, data analysis/ interpretation, writing all/sections of the manuscript, and manuscript revision;DVDBR: Study design, data analysis/interpretation, writing all/sections of the manuscript, and manuscript revision.

\section{CONFLICT OF INTEREST}

The authors declare that they have no conflicts of interest.

\section{REFERENCES}

1. Ding X, Yan D, Sun W, Zeng Z, Su R, Su J. Epidemiology and risk factors for nosocomial non-Candida albicans candidemia in adult patients at a tertiary care hospital in North China. Med Mycol. 2015;53(7):684-90.
2. Gaona-Flores VA, Campos-Navarro LA, Cervantes-Tovar RM, AlcaláMartínez E. The epidemiology of fungemia in an infectious diseases hospital in Mexico city: a 10-year retrospective review. Med Mycol. 2016;54(6):600-04.

3. Ulu Kilic A, Alp E, Cevahir F, Ture Z, Yozgat N. Epidemiology and cost implications of candidemia, a 6-year analysis from a developing country. Mycoses. 2017;60(3):198-203.

4. Giacobbe DR, Esteves P, Bruzzi P, Mikulska M, Furfaro E, Mesini A, et al. Initial serum (1,3)- $\beta$-D-glucan as a predictor of mortality in proven candidaemia: findings from a retrospective study in two teaching hospitals in Italy and Brazil. Clin Microbiol Infect. 2015; 21(10):954. e9-17.

5. Canela HM, Cardoso B, Vitali LH, Coelho HC, Martinez R, Ferreira ME. Prevalence, virulence factors and antifungal susceptibility of Candida spp. isolated from bloodstream infections in a tertiary care hospital in Brazil. Mycoses. 2018;61(1):11-21.

6. Lenardt MH, Betiolli SE, Willig MH, Lourenço TM, Carneiro NH, Melo ND. Fatores de risco para mortalidade de idosos com infecção do sítio cirúrgico. Rev Bras Geriatr Gerontol. 2010;13(3):383-93.

7. Loss SH, Oliveira RP, Maccari JG, Savi A, Boniatti MM, Hetzel MP. The reality of patients requiring prolonged mechanical ventilation: a multicenter study. Rev Bras Ter Intensiva. 2015;27(1):26-35.

8. Falcone M, Tiseo G, Tascini C, Russo A, Sozio E, Raponi G, et al. Assessment of risk factors for candidemia in non-neutropenic patients hospitalized in Internal Medicine wards: a multicenter study. Eur J Intern Med. 2017;41:33-8.

9. Kurihayashi AY, Caruso L, Soriano FG. Terapia nutricional parenteral em UTI: aplicação dos indicadores de qualidade. Mundo Saude. 2009;33(4):480-7.

10. Savastano C, de Oliveira Silva E, Gonçalves LL, Nery JM, Silva NC, Dias AL. Candida glabrata among Candida spp. from environmental health practitioners of a Brazilian hospital. Braz J Microbiol. 2016;47(2):367-72.

11. Colombo AL, Guimarães T, Sukienik T, Pasqualotto AC, Andreotti R, Queiroz-Telles F, et al. Prognostic factors and historical trends in the epidemiology of candidemia in critically ill patients: an analysis of five multicenter studies sequentially conducted over a 9-year period. Intensive Care Med. 2014;40(10):1489-98.

12. Singh A, Goering RV, Simjee S, Foley SL, Zervos MJ. Application of Molecular Techniques to the Study of Hospital Infection. Clinical microbiology reviews. 2006;19(3): 512-30.

13. Brilhante RSN, Sales JA, da Silva MLQ, de Oliveira JS, Pereira LA, Pereira-Neto WA, et al. Antifungal susceptibility and virulence of Candida parapsilosis species complex: an overview of their pathogenic potential. J Med Microbiol. 2018;67(7):903-14.

14. Silva S, Negri M, Henrique M, Oliveira R, Williams DW, Azeredo J. Candida glabrata, Candida parapsilosis and Candida tropicalis: biology, epidemiology, pathogenicity and antifungal resistance. FEMS Microbiol Rev. 2012;36(2):288-305.

15. Motta FA, Dalla-Costab LM, Murob MD, Cardoso MN, Picharski GL, Jaeger $\mathrm{G}$, et al. Risk factors for candidemia mortality in hospitalized children. J Pediatr. 2017;93(2):165-71.

16. Liu WL, Lai CC, Li MC, Wu CJ, Ko WC, Hung YL, et al. Clinical manifestations of candidemia caused by uncommon Candida species and antifungal susceptibility of the isolates in a regional hospital in Taiwan, 2007-2014. J Microbiol Immunol Infect. 2017;17:1-8. 